\section{Claude Lévi-Strauss, quatro décadas depois: As mitológicas}

Claude LÉVI-STRAUSS. O cru e o cozido. Mitológicas 1. São Paulo, CosacNaify, 2004. 442 páginas. Claude LÉVI-STRAUSS. Do mel às cinzas. Mitológicas 2. São Paulo, CosacNaify, 2004. 500 páginas.

\section{Roque de Barros Laraia}

No quadragésimo aniversário do início da publicação de As mitológicas, de Claude LéviStrauss, a editora Cosacnaify tomou a iniciativa de publicar toda a coleção em português. Considero que se trata de um fato de grande importância, pois os livros O cru e o cozido [1964], Do mel às cinzas [1967], A origem dos modos à mesa [1968] e O bomem nu [1973] nunca foram traduzidos integralmente no Brasil e são inacessíveis para as novas gerações de antropólogos e demais estudioso interessados no estudo das mitologias.

Aceitar a tarefa de escrever sobre esse empreendimento editorial é muito estimulante para mim, uma vez que faço parte de uma geração de antropólogos brasileiros que, há quarenta anos, se empolgou com a leitura de $O \mathrm{cru}$ e o cozido e, nos anos subseqüentes, aguardou com ansiedade o lançamento dos demais volumes. E não foram somente os antropólogos que participaram desse entusiasmo: no Rio de Janeiro, um grupo de intelectuais reunia-se em um bar chamado Zepelin para discutir, noite à dentro, as últimas novidades do estruturalismo de Lévi-Strauss. Não fiz parte desse grupo, mas de um outro grupo de jovens pesquisadores do Museu Nacional, então empenhados na realização de trabalho de campo entre grupos indígenas e que encontraram no método estruturalista o caminho para compreender as narrativas míticas, cujos fragmentos ouvíamos dos anciões, ao redor de fogueiras. Com a ajuda dos textos de Lévi-Strauss foi possível publicar um série de artigos sobre a mitologia indígena brasileira, como, por exemplo, os que fizeram parte da publicação Tempo brasileiro, mito e linguagem social, que incluiu artigos de Roberto Cardoso de Oliveira, Roberto DaMatta, Júlio César Melatti e Roque de Barros Laraia. Portanto, é muito gratificante escrever esta resenha "tardia" para ser lida pela nova geração de estudiosos do tema.

O interesse de Lévi-Strauss pela análise dos mitos corporificou-se, em 1955, com a publicação de seu artigo "The structural study of myth" (Journal of American Folklore, 78 [270]), republicado, com algumas modificações, em sua famosa coletânea Anthropologie structurale (Paris, Librarie Plon, 1958). É neste artigo que o autor formula o princípio básico de seu método de análise, qual seja, um mito não existe isoladamente, ele está relacionado com outros mitos. A sua interpretação somente se torna possível quando analisado conjuntamente com outros grupos de mitos que lhes são próximos.

O germe do pensamento de Lévi-Strauss encontra-se na epígrafe do artigo supracitado: "Diz-se-ia que os universos mitológicos são destinados a ser pulverizados mal acabam de se formar, para que novos universos nasçam de seus fragmentos" (Franz Boas). Com efeito, na "Introdução" de O cru e o cozido, Lévi-Strauss utiliza-se da metáfora cósmica para se referir às transformações dos sistemas mitológicos: "À medida que a nebulosa se expande, portanto, o seu núcleo se condensa e se organiza. Filamentos esparsos se soldam, lacunas se preenchem, conexões se estabelecem, algo que se assemelha a uma ordem transparece sobre o caos. Como numa molécula germinal, seqüências onde ondas em grupos de transformações vêm agregar-se ao grupo inicial, reproduzindo-lhe a estrutura e as determinações. Nasce um corpo multidimensional, cuja organização é revelada nas partes centrais, enquanto em sua periferia reinam ainda a incerteza e a confusão" (p. 21).

Ao considerar os sistemas mitológicos como sistemas em transformações, Lévi-Strauss aproxima-se, uma vez mais, da lingüística. Sabe-se que baseou a elaboração de seu estruturalismo na lingüística estrutural, como mostrou Roberto Cardoso de Oliveira no artigo "Estruturalismo e estruturalistas na antropologia social" (Tempo Brasileiro, 15-16, s/d). A influência da lingüística na obra de Lévi-Strauss foi certamente ocasionada pelo estreito relacionamento do autor com o lin- 
güista russo Roman Jacobson, quando ambos, como refugiados, viveram nos Estados Unidos durante a Segunda Guerra Mundial, conforme consta de seu depoimento a Didier Eribon.

É também interessante lembrar que ao mesmo tempo em que desenvolvia suas idéias a respeito de transformações, o lingüista norte-americano Noam Chomsky - professor do Massachussets Institute of Technology, em Boston - publicava o livro Syntatic structures (Haia, Mouton \& Co., 1957), responsável "pela ampliação dos modelos já existentes ao se estipularem [...] as regras de transformação - pedra angular da teoria chomskyana - e ao postularem dois tipos de estruturas ligadas pelas regras de transformação: a estrutura subjacente e a estrutura de superfície" (Lemle e Leite [orgs.], Novas perspectivas lingüisticas, Petrópolis, Vozes, 1970, p. 6).

Não resta dúvida de que a teoria transformacional de Chomsky influenciou Lévi-Strauss. Aliás, foi também na lingüística que ele buscou, por analogia, o termo mitema (da mesma natureza de fonema) para designar uma unidade constitutiva do mito.

A partir da formulação transformacionista, entende-se que a análise dos mitos somente é possível de ser feita por seus fragmentos, pois "trata-se de uma realidade instável permanentemente à mercê dos golpes de um passado que a arruina e de um futuro que a modifica ( $O$ crú e $o$ cozido, p. 21). Este fato explica a sensação de insatisfação do antropólogo ao coletar trechos de mitos que sempre lhes parecem não passar de fragmentos ou peças esparsas de um imenso quebra-cabeça, cujos elementos principais parecem irremediavelmente perdidos.

Em O cru e o cozido, que, segundo o próprio autor, poderia também ser chamado de "representações míticas da passagem da natureza à cultura”, foram analisados 187 mitos coletados por diversos pesquisadores entre povos indígenas do Brasil. Os Bororo, índios do grupo lingüístico Macro-Jê do Brasil Central, contribuíram com dezoito narrativas que representam variações de um mesmo tema e que foram considerados "mitos de referência". Todos os 187 mitos utilizados referem-se "direta ou indiretamente à invenção do fogo e, portanto, da cozinha, enquanto símbolo no pensamento indígena. Da passagem da natu- reza à cultura" (Lévi-Strauss, Minhas palavras, São Paulo, Brasiliense, 1986, p. 51). O leitor surpreende-se com o fato de que exatamente os mitos Bororo tomados como referência são exatamente os que menos explicitam a conquista do fogo. O próprio autor reconhece: "temos razões para admitir que o mito Bororo se refere à origem do fogo apesar de sua extrema discrição quanto a isso" (O cru e o cozido, p. 169). Mitos Tupi, que fazem parte do livro, são mais diretos: o herói mítico finge que morreu e atrai os urubus. Estes, que eram então os donos do fogo, juntam-se em volta do morto e acendem uma fogueira para cozinhá-lo. O herói afugenta os urubus e toma posse do fogo, entregando-o aos homens. O leitor poderá, no entanto, acompanhar todo o procedimento de análise do autor para demonstrar a semelhança dos demais mitos com os de referência e, principalmente, compreender que o cru é a metáfora da natureza e o fogo, da cultura. Animais comem carne crua, homens, carne cozida. O que os mitos dizem é que houve um tempo em que essa relação estava invertida: com o roubo do fogo os homens transformam-se em caçadores e os animais, em caça.

O primeiro volume d'As mitológicas diferencia-se dos demais por ter sido organizado em partes com denominações musicais: Abertura, Canto Bororo, Sonata das Boas Maneiras, Fuga dos Cinco Sentidos, Sinfonia Breve, Cantata etc. Isso encantou os leitores em várias línguas, mas as intenções do autor foram pouco compreendidas. Em 1988, em entrevista a Didier Eribon, LéviStrauss explicou por que em sua Abertura faz referência a Wagner, a quem reconhece como uma grande influência em sua formação. Afirmou que "Wagner não só construiu suas óperas sobre mitos, mas deles propõem um recorte que o emprego dos leitmotive torna explícito: o leitmotive prefigura o mitema". A estrutura dos mitos teria, então, a ver com uma organização musical, mas os índices dos demais volumes diluem essa informação. O autor, contudo, assegura que a organização musical continua presente no restante da obra.

Se no primeiro volume, a dicotomia básica é o cru e o cozido, o segundo volume, Do mel às cinzas, trata da oposição entre o mel e o tabaco. O mel está ligado à idéia de natureza e o tabaco, 
ao mundo sobrenatural. Em sua empreitada analítica, Lévi-Strauss trabalhou com 165 mitos, que extrapolam os limites da América do Sul, ao contrário do que acontece no primeiro volume. No entanto, O cru e o cozido trabalha com categorias que podem ser consideradas universais, ao passo que Do mel às cinzas permanece circunscrito a uma dicotomia exclusivamente americana. Apenas o mel possui a mesma amplitude: "As metáforas inspiradas pelo mel se incluem entre as mais antigas de nossa língua e de outras que a precederam. Os hinos védicos associam freqüentemente o leite e o mel, os quais, segundo a Bỉblia, fluirão pela terra prometida. 'Mais doce que o mel' são as palavras do Senhor. O mel era a oferenda por excelência que os babilônios faziam aos deuses, pois estes exigiam um alimento que não tivesse sido tocado pelo fogo. $\mathrm{Na}$ Ilíada, as jarras servem de oferendas aos mortos" (p. 13). Lévi-Strauss chama a atenção para o fato de que o mel e o fumo são substâncias comestíveis, "mas nem um nem outro dizem respeito à cozinha”. O mel é o produto das abelhas e já está pronto para o consumo; o fumo é incinerado para que a sua fumaça possa ser aspirada. Ao contrário do mel, o tabaco era desconhecido pelos habitantes de outros continentes até a chegada dos europeus na América, por isso o conhecimento de ambos os produtos era exclusivo da América do Sul.

Enfim, esses dois volumes proporcionará uma leitura estimulante para antropólogos ou não. É preciso destacar ainda o cuidado primoroso com a edição e, principalmente, a excelente tradução de Beatriz Perrone-Moisés

\section{ROQUE DE BARROS LARAIA é professor titular de antropologia da Universidade Católica de Goiás e professor emérito da Universidade de Brasília.}

\section{A Nova Ortodoxia Judaica em São Paulo}

\author{
Marta F. TOPEL, Jerusalém \& São Paulo: a nova \\ ortodoxia judaica em cena. Rio de Janeiro, \\ Topbooks, 2005. 313 páginas.
}

\section{Gabriel Bolaffi}

Durante a sua história milenar, o judaísmo foi sempre arejado ou sacudido por inúmeros vendavais renovadores. Para não ir longe demais, lembremos o falso messias Shabtai Zvi, no século XVII, o movimento Hassídico e seus opositores (Mitnagdim), no século XVIII, e que até hoje tem seus adeptos, ou quase. O iluminismo judeu, deslanchado por Napoleão quando emancipou os judaicos na França e nos países invadidos, o judaísmo ortodoxo, reação ao iluminismo, o Sionismo e, finalmente, o judaísmo comunista, ao qual Stalin prometera uma República JudiaSoviética, para não falar no judaísmo reformado e outros menores. Como é sabido, a maioria dessas inovações foi gerada por eventos históricos alheios aos judaicos, como as Matanças de Chemielnicky (1654), o Pogrom ${ }^{1}$ de Kishinev e outras manifestações de anti-semitismo.

Felizmente, no Brasil nunca houve problemas dessa ordem ou similares. Não obstante, de um par de décadas para cá, cidadãos paulistanos e de outras cidades grandes do país, principalmente em bairros de classe média alta como Higienópolis ou Jardim Paulista, em São Paulo, estão cada vez mais curiosos e intrigados. Quem são esses senhores, senhoras e crianças pálidas vestidos de preto, os homens, trajando uma túnica, com longas barbas e longos cachos nas temporas, sempre de chapéu e mulheres muitas vezes usando perucas, que andam em grupos, geralmente ao cair da noite? Os que alguns chamam de "pinguins" em virtude da túnica preta sobre a camisa branca? É o que a antropóloga Marta F. Topel, da USP, procura explicar no seu interessante livro, recém-publicado, Jerusalém \& São Paulo: a nova ortodoxia judaica em cena.

Os judeus começaram a chegar no Brasil no final do século XIX e no decorrer do século seguinte; vieram das regiões mais díspares do velho 